Provided for non-commercial research and education use. Not for reproduction, distribution or commercial use.

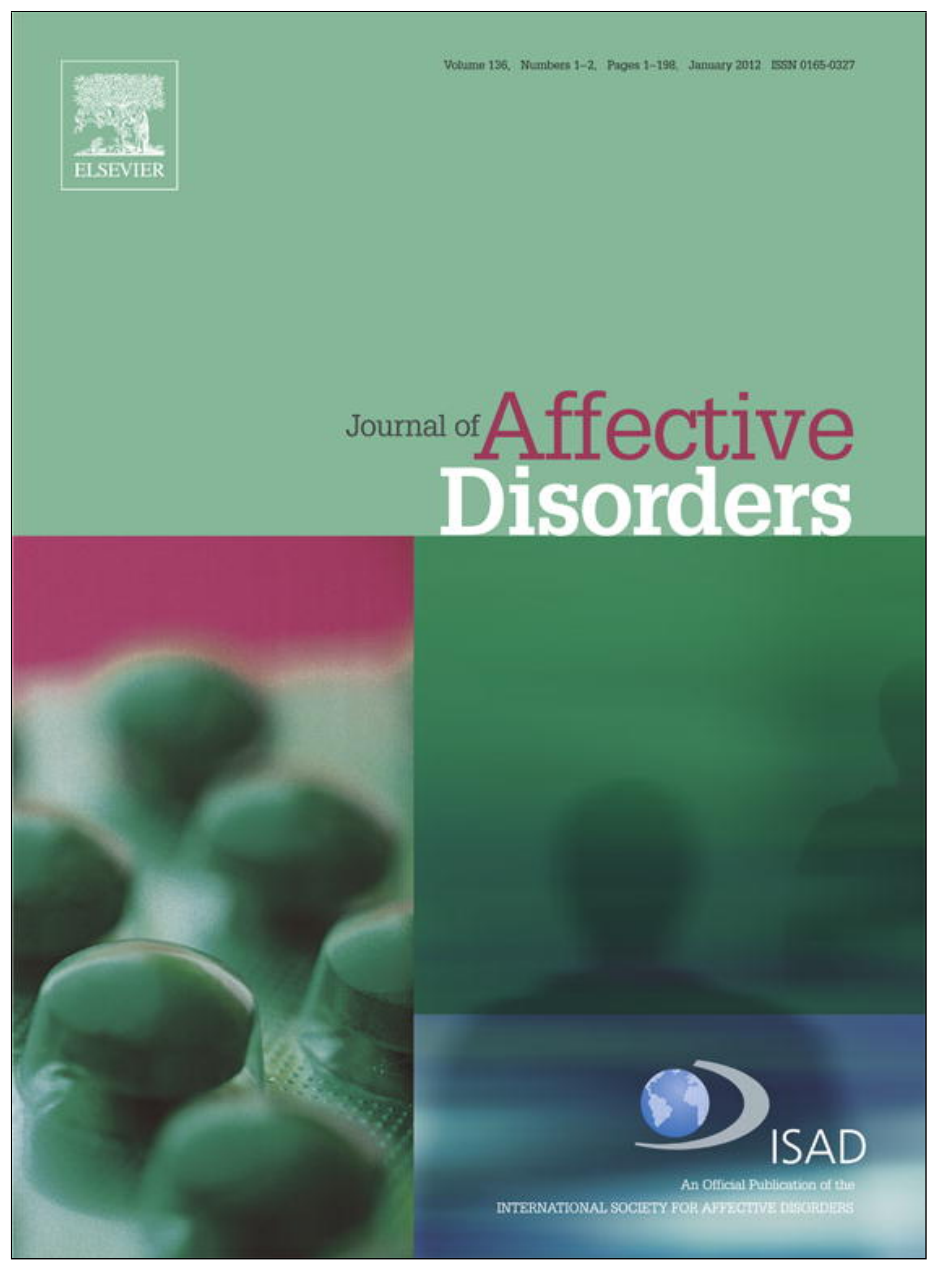

This article appeared in a journal published by Elsevier. The attached copy is furnished to the author for internal non-commercial research and education use, including for instruction at the authors institution and sharing with colleagues.

Other uses, including reproduction and distribution, or selling or licensing copies, or posting to personal, institutional or third party websites are prohibited.

In most cases authors are permitted to post their version of the article (e.g. in Word or Tex form) to their personal website or institutional repository. Authors requiring further information regarding Elsevier's archiving and manuscript policies are encouraged to visit:

http://www.elsevier.com/authorsrights 
Research report

\title{
Dissociation, shame, complex PTSD, child maltreatment and intimate relationship self-concept in dissociative disorder, chronic PTSD and mixed psychiatric groups
}

\author{
Martin J. Dorahy a,b,*, Warwick Middleton ${ }^{\mathrm{a}, \mathrm{b}}$, Lenaire Seager ${ }^{\mathrm{b}}$, Patrick McGurrin ${ }^{\mathrm{b}}$, \\ Mary Williams ${ }^{\mathrm{b}}$, Ron Chambers ${ }^{\mathrm{c}}$ \\ ${ }^{a}$ Department of Psychology, University of Canterbury, Christchurch, New Zealand \\ ${ }^{\mathrm{b}}$ The Cannan Institute, Belmont Private Hospital, Brisbane, Australia \\ ${ }^{\mathrm{c}}$ Anxiety Disorders Service, Canterbury District Health Board, Christchurch, New Zealand
}

\section{A R T I C L E I N F O}

\section{Article history:}

Received 19 August 2014

Received in revised form

1 October 2014

Accepted 1 October 2014

Available online 12 October 2014

Keywords:

Dissociation

Shame

Complex PTSD

Relationships self-concept

\begin{abstract}
A B S T R A C T
Background: Whilst a growing body of research has examined dissociation and other psychiatric symptoms in severe dissociative disorders (DDs), there has been no systematic examination of shame and sense of self in relationships in DDs. Chronic child abuse often associated with severe DDs, like dissociative identity disorder, is likely to heighten shame and relationship concerns. This study investigated complex posttraumatic stress disorder (PTSD), borderline and Schneiderian symptoms, dissociation, shame, child abuse, and various markers of self in relationships (e.g., relationship esteem, relationship depression, fear of relationships).

Methods: Participants were assessed via clinical interview with psychometrically sound questionnaires. They fell into three diagnostic groups, dissociative disorder $(n=39$; primarily dissociative identity disorder), chronic PTSD (Chr-PTSD; $n=13$ ) or mixed psychiatric presentations (MP; $n=21$; primarily mood and anxiety disorders). All participants had a history of child abuse and/or neglect, and the groups did not differ on age and gender.

Results: The DD group was higher on nearly all measured variables than the MP group, and had more severe dissociative, borderline and Schneiderian symptoms than the Chr-PTSD sample. Shame and complex PTSD symptoms fell marginally short of predicting reductions in relationship esteem, pathological dissociative symptoms predicted increased relationship depression, and complex PTSD symptoms predicted fear of relationships.

Limitations: The representativeness of the samples was unknown.

Conclusion: Severe psychiatric symptoms differentiate DDs from chronic PTSD, while dissociation and shame have a meaningful impact on specific markers of relationship functioning in psychiatric patients with a history of child abuse and neglect.
\end{abstract}

(c) 2014 Elsevier B.V. All rights reserved.
Early relational trauma may be associated with dissociation, the self-conscious emotions of shame and guilt, deficiencies in selfhood and a broad spectrum of relationship problems (Andrews et al., 2000; Dalenberg et al., 2012; Middleton, 2012; Talbot et al., 2004; Thomson and Jaque, 2013), which have been routinely discussed in the dissociative disorders (DDs) treatment literature (e.g., Boon et al., 2011; Chu, 2011; Van der Hart et al., 2006). Yet little empirical work has collectively examined pathological dissociation, shame and relationship self-concept in severe DDs, or assessed how dissociation and shame might predict self-concept

\footnotetext{
* Corresponding author at: Department of Psychology, University of Canterbury, Private Bag 4800, Christchurch 8140, New Zealand

E-mail address: martin.dorahy@canterbury.ac.nz (M.J. Dorahy).
}

("how a person describes and feels about him/herself", Hinde et al., 2001, p. 189) in relationships (i.e., relationship self-concept). The current study extends on previous work in complex posttraumatic stress disorder (PTSD; Dorahy et al., 2013) by addressing these issues in a DDs sample largely made up of participants with dissociative identity disorder (DID), and two psychiatric comparison groups reporting child abuse and neglect histories.

Phenomenological studies comparing DID with other psychiatric groups have reported high incidences of dissociative, psychotic, borderline, anxiety and depressive symptoms in DID groups (Middleton and Butler, 1998; Nijenhuis et al., 1999; Rodewald et al., 2011; Ross and Ness, 2010; Şar et al., 1996; see Dorahy et al., 2014). In therapy emotions like shame and guilt, as well as anxiety and fear associated with relationships are likely to be centrally important, especially in the development of a working relationship 
and addressing dissociative and trauma dynamics (Boon et al., 2011; Chu, 2011; Howell, 2011).

For example, shame is thought to impinge significantly on social functioning (Gruenewald et al., 2007; Tracy and Robins, 2007) and brings about self-directed appraisals of having reduced social value and acceptance (e.g., Gilbert and McGuire, 1998; Harder and Lewis, 1987). When shame is evoked, social functioning is likely to suffer and interpersonal relationships erode (Mollon, 2006). In traumatized samples, shame has been associated with heightened feelings of disconnectedness in relationships (Budden, 2009; Dorahy, 2010; Lee et al., 2001). Interestingly however, in a sample with chronic PTSD associated with civil conflict, shame was not found to predict markers of relationship self-concept (e.g., fear of relationships, relationship depression) when complex trauma symptoms and dissociation were included (Dorahy et al., 2013). Yet, avoidance as a way of managing shame was a unique predictor of fear of relationships in this sample. Nathanson (1992) notes four behavioural responses activated to manage the pain of shame, which form the "compass of shame". To stave off shame or deal with it once it is experienced an individual may respond with social/interpersonal avoidance or withdrawal. Alternatively, they may defend against the feeling by attacking themselves or attacking another (Elison et al., 2006). The clinical applications of the compass of shame have been outlined in severely traumatized, dissociative patients (Kluft, 2007). However, little empirical research has examined either shame or the compass of shame in those with dissociative disorders.

Related to shame, but distinct from it, guilt has also been associated with trauma-related disorders (Lee et al., 2001; Wilson et al., 2006). Guilt is typically understood to relate to an action or behaviour which transgresses social or moral codes, or an individual's beliefs (Lee et al., 2001; Tangney, 1996). It activates efforts to repair damage or in the absence of reparation, punishes the self for the transgression. Work has noted a relationship between guilt and dissociative symptoms (Dorahy and Schumaker, 1997; Irwin, 1998), but little research has examined guilt and its association to relational functioning in DDs.

Dissociative symptoms are heightened in those with trauma and dissociative disorders (Dalenberg et al., 2012). Such symptoms appear to be activated by intrapsychic processes, which may serve to moderate emotional distress by disrupting integration of painful psychological and somatic experiences. Dissociation may also serve to moderate, by way of disruption, a sense of connexion in relationships (Lyons-Ruth, 2008). Lyons-Ruth (2003) has argued that when an individual is experiencing a dissociative episode, such as feeling detached from their body, it has a significant impact on their ability to stay connected in that moment to another person. Having a dissociative experience (e.g., ego-observing depersonalization) while relating to others may become a default means of reducing the felt sense of connexion. A patient exemplified the devastating impact dissociation can have on relational functioning; "they [her children] were talking about some things that happened several years ago, going through the events, but I couldn't remember any of them. I felt so disconnected, I just shut up and pretended I knew, but didn't feel part of what was going on. I never feel a part of what is going on." Dissociation can therefore have a considerable effect on the ability to sustain emotional relationships. Consequently, as Lyons-Ruth (2008) notes, dissociation is both an intrapsychic (i.e., way of relating to self) and interpersonal (way of relating to others) process. Dissociation therefore reflects fragmentation of a coherent relational self (Lyons-Ruth, 2008). Still to be empirically deciphered is which components of the complex construct of relationship selfconcept are most impacted on by dissociation.

Among the numerous and complex variables associated with relationship self-concept are people's psychological tendencies in intimate relationships (Middleton, 2005, 2012). For example, whether intimate relationships preoccupy their thinking, whether they feel anxiety in, or depressed about, their intimate relationships, or whether they fear intimate connexion (Snell et al., 1996). In a complex PTSD sample, dissociation was associated with relationship preoccupation and fear of relationships (Dorahy et al., 2013). Complex PTSD symptom severity predicted relationship anxiety, relationship depression and fear of relationships. Complex PTSD symptoms manifest as alterations in numerous basic psychobiological processes (Pelcovitz et al., 1997) associated with affect regulation (e.g., impulsivity, self harm), attention/consciousness (i.e., dissociation), selfperception (e.g., shame, guilt), relationships with others (e.g., mistrust), somatic functioning (e.g., psychosomatic pain) and meaning in life (e.g., despair at future). Dorahy et al. (2013) did not parcel out the dissociation symptoms from the other complex PTSD symptoms when examining the predictive power of the severity of complex PTSD and dissociative symptoms on various aspects of relationship self-concept.

In investigating the impact of shame, guilt, dissociation and complex PTSD symptoms on relationship self-concept in clinical samples with childhood abuse and neglect histories, the current study removed the dissociative symptoms from the complex PTSD measure and dissociation was assessed via a dissociation-specific tool. This allowed a more sensitive assessment of the independent contribution of dissociative symptoms to relationship self-concept. In addition, the complex PTSD measure did not directly assess shame, so shame was also assessed more fully and independently by a shame-specific measure. It was predicted that shame and dissociation would be significantly related to intimate relationship selfconcept (i.e., anxiety, depression, fear, esteem). All participants had a history of child abuse and neglect and had a diagnosis of (1) dissociative disorder (primarily DID), (2) child maltreatmentrelated chronic PTSD or (3) another psychiatric problem. Given the literature showing high levels of abuse and neglect in DID, along with a complex and severe symptom profile (Dorahy et al., 2014), it was expected that the DD sample would have a higher level of childhood abuse/neglect and higher scores on the symptom and affect measures.

\section{Method}

\subsection{Participants}

The study assessed individuals with a psychiatric diagnosis of DID $(n=36)$ along with a comparison sample of aged-matched psychiatric individuals who had a history of child abuse and/or neglect, but did not have DID ( $n=37$; chronic PTSD, $n=13$; other specified dissociative disorder, $n=3$; non-PTSD anxiety and/or mood disorders, $n=21$ ). However, conceptual and empirical considerations during and after data collection required a reappraisal of how the overall sample was divided. First, three participants had a clinical diagnosis of Other Specified Dissociative Disorder-type 1 (formerly dissociative disorder not otherwise specified-type 1), which is effectively the same as DID but without the amnesia criterion met. One of these participants was positive on the Dissociative Disorder Interview Schedule (DDIS; Ross et al., 1989a) for DID, while five clinically diagnosed DID participants, who were further along in treatment and now reported little amnesia, showed up as OSDD-type 1 on the DDIS. As a result of these overlapping features, the OSDD participants were included in the DID sample. Second, in order to get a mixed psychiatric sample, efforts were made to include a range of mood (major depressive disorder; bipolar disorder) and anxiety disorders. Thirteen of those in the mixed psychiatric group had a diagnosis of chronic posttraumatic stress disorder (Chr-PTSD). During exploratory data analysis, this group looked different to the mixed psychiatric sample on a range 
of variables. Thus a decision was made to treat them as a separate sample. Consequently, the study examined variables across 3 groups, (1) Dissociative Disorders (DD), (2) Chr-PTSD and (3) mixed psychiatric (MP).

The DD sample contained 36 participants with a psychiatrist diagnosis of DID and three participants with a psychiatrist diagnosis of OSDD $(n=39)$. All met diagnostic criteria for DID or OSDDtype 1 on the DDIS.

The Chr-PTSD sample contained 13 participants with chronic PTSD. All Chr-PTSD participants had a history of long and complicated trauma-related symptoms. No participant in this sample was positive for DID or OSDD-type 1 on the DDIS, though on items 12, 13 and 28 of the Dissociative Experiences Scale, which all assess derealisation and depersonalization, 11 participants reported such experiences, suggesting they may have been positive for DSM-5's dissociative subtype of PTSD.

The MP sample contained 21 participants. None were positive for a dissociative disorder on the DDIS.

\subsection{Procedure and materials}

Participants were informed of the study via an invitation letter given to them by nursing staff or clinical staff involved in their care (e.g., therapists/psychiatrists). Following completion of consent forms, participants were administered in clinical interview format the Stress Reactions Checklist for Disorders of Extreme Stress (SRC; Ford et al., 2007), the Dissociative Experiences Scale (DES; Carlson and Putnam, 1993), the Childhood Trauma Questionnaire (CTQ; Bernstein and Fink, 1998), the Multidimensional Relationship Questionnaire (MRQ; Snell et al., 1996), the Personal Feelings Questionnaire-2 (PFQ-2; Harder and Lewis, 1987), the Compass of Shame Scale (CoSS; Elison et al., 2006), the State Shame and Guilt Scale (SSGS; Marschall et al., 1994) and the borderline, dissociation, and first rank symptoms sections of the DDIS. The presentation of questionnaires was randomized and administered by well-trained clinicians (e.g., MJD, LS) or final year postgraduate clinical psychology students. Interviews typically took between 45 and $90 \mathrm{~min}$, with some DD participants needing longer to manage distress and/ or fatigue. Participants were debriefed before leaving the assessment session, and offered contacts for post-interview support if needed. The study was approved by the relevant ethics committees.

The SRC was designed as a short screener of complex PTSD symptoms. Its 17 items are assessed on a 0 (none of the time) to 4 (all of the time) point scale (range: 0-68). The SRC does not directly assess shame. Three items directly assess dissociation, in the form of derealisation and depersonalization. The SRC has good psychometric properties (e.g., Ford et al., 2007).

The DES comprises 28 items tapping both pathological and non-pathological types of dissociation (Waller et al., 1996). Respondents indicate on an 11-point scale from $0 \%$ (never) to $100 \%$ (always) how often they experience each item. Collectively, eight items of the DES (known as the Dissociative Experiences Scale-Taxon; DES-T) have been shown to index pathological dissociative tendencies (Waller et al., 1996). The total DES score is the mean of the 28 items (DES-T total score is the mean of its eight items). The psychometric properties of the DES are well supported (see Van IJzendoorn and Schuengel, 1996).

The CTQ is a self-report inventory screening for histories of child abuse and neglect over 28 items. Responses are made on a scale from "never true" (1) to "very often true" (5). The CTQ contains 5 subscales (Childhood Emotional Abuse, Childhood Physical Abuse, Childhood Sexual Abuse, Childhood Physical Neglect, and Childhood Emotional Neglect), which when averaged together provides an overall metric for childhood abuse and neglect severity. Total score for each participant is reported here. The CTQ has shown good reliability and validity (Bernstein and Fink, 1998).
Seven subscales from the MRQ were administered to measure self-concept in intimate relationships. These subscales were: Relationship Esteem (i.e., positive evaluation of one's capacity as an intimate partner), relationship preoccupation (i.e., becoming engrossed in intimate aspects of one's life), relationship motivation (i.e., motivation to pursue intimacy in life), relationship satisfaction (i.e., fulfilment of intimacy needs and expectations), relationship anxiety (i.e., anxious feelings associated with one's intimate relationships), relationship depression (i.e., negative evaluation of one's intimate relationships), and fear of relationships (i.e., fear of engaging in intimate relationships). Each subscale contains 5 items. Responses are made from 0 (Not at all characteristic of me) to 4 (Very characteristic of me). Some subscales were anchored to a specific intimate relationship, defined as a close relationship with another person in which there is attraction.

The PFQ-2 is a 22 item scale measuring trait shame (10 items) and trait guilt (6 items). A 5 point scale ranging from 0 (never experienced the feeling) to 4 (experience the feeling continuously or almost continuously) is used to rate items. The PFQ-2 has shown good psychometric properties (e.g., Harder, 1995; Harder and Lewis, 1987).

The CoSS measures Nathanson's (1992) four behavioural responses to shame: avoidance, withdrawal, attack self, and attack other (Elison et al., 2006). The scale contains 12 superordinate situations/ questions which require participants to indicate the degree they would engage in avoidance, withdrawal, attacking self or attacking another. Responses range from 1 (never) to 5 (almost always). The CoSS is a psychometrically sound instrument (Elison et al., 2006).

The SSGS assesses state shame (5 items), guilt (5 items) and pride ( 5 items), that is, the feeling of shame, guilt and pride experienced at the time of completing the measure. Items are responded to on a 5 point scale ranging from 1 (not feeling this way at all) to 5 (feeling this way very strongly). The SSGS has shown good psychometric properties (Tangney and Dearing, 2002).

The DDIS is a 132 item structured interview for the detection of DSM-IV dissociative disorders and related symptoms and diagnostic categories. The DDIS has displayed good sensitivity for detecting true cases of DID (Ross, 1995) and the Kappa coefficient for detecting agreement between clinical judgement and DDIS indications of DID is over .9 (e.g., Ross et al., 1989a). The current study utilized the following sections from the DDIS: Positive (Schneiderian) symptoms of schizophrenia (13 items), Borderline Personality Disorder (9 items), Features associated with Dissociative Identity Disorder (16 items) and Dissociative Identity Disorder (4 items). The two latter sections were used to determine the presence or absence of a DD diagnosis.

\subsection{Analysis}

Multivariate analysis of variance (MANOVA) examined group differences on questionnaire variables. As some participants selectively failed to complete some questionnaires a single MANOVA on all variables was not conducted because it would have only included participants completing all questionnaires. Thus, MANOVA was used on each psychological domain assessed - that is DDIS (Schneiderian \& BPD symptoms); DES (total dissociation \& DES-T), Compass of shame variables (withdrawal, avoidance, attack self, attack other), trait and state self conscious emotions (shame, guilt, pride), Complex PTSD symptoms (with and without dissociative items), and relationship variables (i.e., relationship esteem, relationship preoccupation, relationship motivation, relationship anxiety, relationship depression, fear of relationships, relationship satisfaction). ANOVA was used to explore group differences in frequency of child abuse and neglect (i.e., total CTQ). Because it was specifically hypothesized that the DD group would be higher on symptom, relationship self-concept and abuse 
variables planned simple contrasts were used to examine differences between this group and both comparison groups.

Of the seven relationship markers assessed, four were isolated as measures of relationship self-concept concern (relationship anxiety, relationship depression, fear of relationships) or relationship selfconcept strength (relationship esteem) and used as criterion variables in hierarchical regression analyses to determine the degree they were predicted by shame, pathological dissociation or the interaction between shame and pathological dissociation. This latter predictor assessed whether dissociation moderated any relationships found between shame and relationship variables. Complex PTSD, trait guilt and child abuse severity are related to pathological dissociation and trait shame (Dorahy et al., 2013; Herman, 2011; Talbot et al., 2004). Thus, to isolate more fully the effects of shame and dissociation on relationship self-concept, complex PTSD symptoms without the dissociation items, trait guilt, and total child abuse scores were entered in the first step of the hierarchical regressions. Trait shame was entered into the second step, pathological dissociation into the third step, and finally the interaction of shame and pathological dissociation was entered in the last step. Multicollinearity was assessed using tolerance below .2 and variance inflation factor (VIF) above 10 (Field, 2013).

\section{Results}

Table 1 shows the demographic data for the DD, Chr-PTSD and MP samples. Participants in the three samples did not differ on age, $F(2,70)=2.06, p=.14$, and gender, $\chi(2)=4.65, p=.10$. Chi-squared statistics were not calculated for ethnicity, marital status, occupation, or living arrangements due to some cells containing zero.

Table 2 shows the means and standard deviations for all questionnaires. MANOVA showed a significant omnibus effect for Schneiderian and borderline symptoms, $V=.42, F(4,138)=9.20$, $p<.001, \eta_{p}^{2}=.21$, with the DD sample higher than the two comparison groups. The MANOVA for the DES and DES-T produced a similar significant result, $V=.54, F(4,138)=12.67, p<.001$, $\eta_{p}^{2}=.27$, with the DD group higher than both comparisons. The overall effect for the Compass of Shame Scale subscales reached significance, $V=.24, F(8,136)=2.26, p=.03, \eta_{p}^{2}=.12$. The DD sample did not differ on any CoSS subscale from the Chr-PTSD sample. Differences were evident from the MP group on withdrawal and attack other, with the DD sample higher on withdrawal and lower on attack other. The omnibus MANOVA for trait and state selfconscious emotions was significant, $V=.33, \quad F(10,134)=2.65$, $p=.005, \eta_{p}^{2}=.17$. The DD group reported more shame and guilt, and less pride than the MP sample, but did not differ from the ChrPTSD sample on these measures. A similar result was found for complex PTSD symptoms with and without dissociative items included, $V=.37, F(4,138)=7.89, p<.001, \eta_{p}^{2}=.19$. The DD sample was higher on both measures than the MP group but not those with Chr-PTSD. For relationship variables, the omnibus MANOVA fell marginally short of significance, $V=.31, F(14,130)=1.68, p=.07$, $\eta_{p}^{2}=.15$. The simple contrast suggested that the DD group was lower on relationship esteem and higher on relationship anxiety, relationship depression and fear of relationships than the MP group. Finally, the ANOVA for total childhood abuse and neglect reached significance, $V=.46, F(2,68)=14.48, p<.001, \eta_{p}^{2}=.30$. The DD group reported higher severity of overall abuse and neglect in childhood than the MP group, but did not differ from the ChrPTSD group.

Table 3 presents the hierarchical regression models for relationship esteem, relationship anxiety, relationship depression and fear of relationships. Assessment of multicollinearity markers showed tolerance above .02 and VIF below 10 in all cases suggesting no concern of excessive overlapping variance for
Table 1

Demographics variables across the three clinical groupings.

\begin{tabular}{|c|c|c|c|}
\hline \multirow[t]{2}{*}{ Age (SD) } & DD $N=39$ & $\begin{array}{l}\text { Chr-PTSD } \\
N=13\end{array}$ & $\mathrm{MP} N=21$ \\
\hline & $\begin{array}{l}44.67 \\
(S D=10.65)\end{array}$ & $\begin{array}{l}38.08 \\
(\mathrm{SD}=8.81)\end{array}$ & $\begin{array}{l}41.62 \\
(S D=11.05)\end{array}$ \\
\hline \multicolumn{4}{|l|}{ Gender } \\
\hline Male & 3 & 2 & 6 \\
\hline Female & 36 & 11 & 15 \\
\hline \multicolumn{4}{|l|}{ Ethnicity } \\
\hline Australian aboriginal & $1(2.56 \%)$ & $0(0)$ & $0(0)$ \\
\hline White European & $38(97.44 \%)$ & $13(100 \%)$ & $21(100 \%)$ \\
\hline \multicolumn{4}{|l|}{ Marital status } \\
\hline Single & $12(30.8 \%)$ & $7(53.8 \%)$ & $13(62 \%)$ \\
\hline Married & $13(33.3 \%)$ & $6(46.2 \%)$ & $4(19 \%)$ \\
\hline Separated/divorced & $14(35.9 \%)$ & $0(0)$ & $4(19 \%)$ \\
\hline \multicolumn{4}{|l|}{ Living circumstance } \\
\hline $\begin{array}{l}\text { Hostel/supported } \\
\text { living }\end{array}$ & $4(10.3 \%)$ & $0(0)$ & $2(9.5 \%)$ \\
\hline Home of origin & $0(0)$ & $0(0)$ & $7(33.3 \%)$ \\
\hline With spouse & $13(33.3 \%)$ & $6(46.2 \%)$ & $4(19.0 \%)$ \\
\hline $\begin{array}{l}\text { Independent with } \\
\text { others }\end{array}$ & $10(25.6 \%)$ & $3(23 \%)$ & $2(9.6 \%)$ \\
\hline Independent alone & $12(30.8 \%)$ & $4(30.8 \%)$ & $6(28.6 \%)$ \\
\hline \multicolumn{4}{|l|}{ Employment ${ }^{*}$ status } \\
\hline Full- or part-time & $8(20.5 \%)$ & $4(30.8 \%)$ & $4(19.0 \%)$ \\
\hline Disability allowance & $22(56.4 \%)$ & $5(38.5 \%)$ & $13(61.9 \%)$ \\
\hline Homemaker & $5(12.8 \%)$ & $1(7.7 \%)$ & $3(14.3 \%)$ \\
\hline Unemployed & $1(2.6 \%)$ & $3(23.1 \%)$ & $1(4.8 \%)$ \\
\hline Student & $2(5.1 \%)$ & $0(0)$ & $0(0)$ \\
\hline
\end{tabular}

* One DID participant did not complete this question.

predictor variables (Field, 2013). The final model for relationship esteem showed that complex PTSD symptoms without dissociation, child abuse severity, trait guilt, trait shame, pathological dissociation and the interaction between shame and dissociation accounted for a significant $29 \%$ of variance, $F(6,63)=4.30, p=.001$. After accounting for variance attributed to child abuse and neglect, trait guilt and pathological dissociation, both trait shame and complex PTSD (without dissociation symptoms) fell marginally short of uniquely contributing to detriments in relationship esteem ( $p=.055, p=.06$, respectively). The final model for relationship anxiety accounted for a significant $36 \%$ of variance, $F(6,63)=$ $5.98, p<.001$. Yet, no variable uniquely contributed to the explained variance in relationship anxiety, although shame trended in the direction of significance $(p=.09)$. The final model for relationship depression accounted for a significant $23 \%$ of variance, $F(6,63)=3.21, p=.008$. With all other variables in the model, pathological dissociation was the only variable to uniquely contribute to significant variance in relationship depression $(p=.02)$. The final model for fear of relationships accounted for a significant $31 \%$ of variance, $F(6,63)=4.75, p<.001$. Complex PTSD symptoms without dissociation was the only variable to uniquely contribute to the explained variance in fear of relationships $(p=.003)$.

\section{Discussion}

This study is the first to systematically investigate specific aspects of relationship self-concept and shame in dissociative disorders. In examining three distinct psychiatric groupings, all with a history of child abuse and neglect, this study supported the prediction that the DD sample would have a different and more severe symptom profile than the Chr-PTSD and MP samples. There was greater overlap with the Chr-PTSD than MP samples. Pathological dissociation significantly predicted relationship depression while trait shame and complex PTSD symptoms (excluding dissociative symptoms) fell just short of 
Table 2

Means and standard deviations for questionnaire measures, and simple contrast statistics in comparison to the DD sample.

\begin{tabular}{|c|c|c|c|c|}
\hline & Scale & $\begin{array}{l}\text { DD } \\
\text { Mean }\end{array}$ & $\begin{array}{l}\text { Chr-PTSD } \\
\text { Mean }\end{array}$ & $\begin{array}{l}\text { MP } \\
\text { Mean }\end{array}$ \\
\hline & Alpha & $(\mathrm{SD})[n]$ & $(\mathrm{SD})[n]$ & $(\mathrm{SD})[n]$ \\
\hline Schneiderian. Sx. & .94 & $\begin{array}{l}7.58 \\
(3.07)[38]\end{array}$ & $\begin{array}{l}4.00 *(3.27)[13] \\
t(69)=-3.72, p<.001,95 \% \mathrm{CI}[-5.50,-1.66]\end{array}$ & $\begin{array}{l}2.33 *(2.65)[21] \\
t(69)=-6.45, p<.001,95 \% \mathrm{CI}[-6.87,-3.62]\end{array}$ \\
\hline BPD Sx & .80 & $\begin{array}{l}6.95 \\
(1.69)[38]\end{array}$ & $\begin{array}{l}5.54 *(2.37)[13] \\
t(69)=-2.02, p=.047,95 \% \mathrm{CI}[-2.80,-.02]\end{array}$ & $\begin{array}{l}4.19^{*}(2.75)[21] \\
t(69)=-4.68, p<.001,95 \% \mathrm{CI}[-3.93,-1.58]\end{array}$ \\
\hline DES Total & .97 & $\begin{array}{l}53.25 \\
(22.17)[39]\end{array}$ & $\begin{array}{l}32.97 *(13.31)[12] \\
t(69)=-3.82, p<.001,95 \% \mathrm{CI}[-30.81,-9.75]\end{array}$ & $\begin{array}{l}15.71^{*}(10.95)[21] \\
t(69)=-8.68, p<.001,95 \% \mathrm{CI}[-46.17,-28.91]\end{array}$ \\
\hline DES-Taxon & .92 & $\begin{array}{l}50.90 \\
(11.17)[39]\end{array}$ & $\begin{array}{l}26.82^{*}(19.66)[12] \\
t(69)=-3.91, p<.001,95 \% \text { CI }[-36.36,-11.79]\end{array}$ & $\begin{array}{l}7.68^{*}(7.36)[21] \\
t(69)=-8.56, p<.001,95 \% \mathrm{CI}[-53.29,-33.15]\end{array}$ \\
\hline CoSS-withdrawal & .84 & $\begin{array}{l}49.62 \\
(6.26)[39]\end{array}$ & $\begin{array}{l}49.85(6.04)[13] \\
t(70)=.10, p=.92,95 \% \mathrm{CI}[-4.30,4.76]\end{array}$ & $\begin{array}{l}43.57^{*}(8.95)[21] \\
t(70)=-3.15, p=.002,95 \% \mathrm{CI}[-9.88,-2.21]\end{array}$ \\
\hline CoSS-avoidance & .62 & $\begin{array}{l}32.46 \\
(6.74)[39]\end{array}$ & $\begin{array}{l}31.92(9.70)[13] \\
t(70)=-.24, p=.81,95 \% \mathrm{CI}[-4.95,3.88]\end{array}$ & $\begin{array}{l}33.29(4.93)[21] \\
t(70)=.44, p=.66,95 \% \mathrm{CI}[-2.91,4.55]\end{array}$ \\
\hline CoSS-attack self & .91 & $\begin{array}{l}48.79 \\
(9.34)[39]\end{array}$ & $\begin{array}{l}50.31(8.51)[13] \\
t(70)=.50, p=.62,95 \% \mathrm{CI}[-4.59,7.61]\end{array}$ & $\begin{array}{l}43.81(10.49)[21] \\
t(70)=-1.93, p=.06,95 \% \mathrm{CI}[-10.14, .17]\end{array}$ \\
\hline CoSS-attack other & .88 & $\begin{array}{l}22.92 \\
(8.44)[39]\end{array}$ & $\begin{array}{l}24.85(8.32)[13] \\
t(70)=.70, p=.48,95 \% \mathrm{CI}[-3.52,7.37]\end{array}$ & $\begin{array}{l}29.43^{*}(8.81)[21] \\
t(70)=2.82, p=.006,95 \% \text { CI }[1.90,11.11]\end{array}$ \\
\hline Trait shame & .84 & $\begin{array}{l}25.28 \\
(6.46)[39]\end{array}$ & $\begin{array}{l}22.38(5.36)[13] \\
t(70)=-1.34, p=.19,95 \% \mathrm{CI}[-7.21,1.42]\end{array}$ & $\begin{array}{l}18.90^{*}(7.94)[21] \\
t(70)=-3.49, p=.001,95 \% \mathrm{CI}[-10.02,-2.73]\end{array}$ \\
\hline Trait guilt & .70 & $\begin{array}{l}15.51 \\
(4.93)[39]\end{array}$ & $\begin{array}{l}15.38(3.59)[13] \\
t(70)=-.93, p=.92,95 \% \mathrm{CI}[-2.88,2.63]\end{array}$ & $\begin{array}{l}12.71^{*}(3.36)[21] \\
t(70)=-2.40, p=.02,95 \% \mathrm{CI}[-5.13,-.47]\end{array}$ \\
\hline State shame & .81 & $\begin{array}{l}15.77 \\
(5.51)[39]\end{array}$ & $\begin{array}{l}14.15(3.99)[13] \\
t(70)=-1.00, p=.32,95 \% \mathrm{CI}[-4.85,1.62]\end{array}$ & $\begin{array}{l}9.69^{*}(4.72)[21] \\
t(70)=-4.44, p<.001,95 \% \mathrm{CI}[-8.81,-3.35]\end{array}$ \\
\hline State guilt & .82 & $\begin{array}{l}15.36 \\
(6.38)[39]\end{array}$ & $\begin{array}{l}15.85(3.60)[13] \\
t(70)=.28, p=.78,95 \% \mathrm{CI}[-2.98,3.95]\end{array}$ & $\begin{array}{l}11.44^{*}(4.23)[21] \\
t(70)=-2.86, p=.006,95 \% \mathrm{CI}[-6.86,-1.00]\end{array}$ \\
\hline State pride & .88 & $\begin{array}{l}10.76 \\
(4.39)[39]\end{array}$ & $\begin{array}{l}9.62(4.46)[13] \\
t(70)=-.78, p=.44,95 \% \mathrm{CI}[-4.05,1.77]\end{array}$ & $\begin{array}{l}13.29 *(4.90)[21] \\
t(70)=2.05, p=.04,95 \% \text { CI }[.07,4.99]\end{array}$ \\
\hline Complex PTSD & .82 & $\begin{array}{l}32.84 \\
(9.06)[38]\end{array}$ & $\begin{array}{l}29.46(9.76)[13] \\
t(69)=-1.21, p=.23,95 \% \mathrm{CI}[-8.97,2.21]\end{array}$ & $\begin{array}{l}18.05^{*}(7.30)[21] \\
t(69)=-6.24, p<.001,95 \% \mathrm{CI}[-19.53,-10.06]\end{array}$ \\
\hline Complex PTSD without dissociative Sx & .80 & $\begin{array}{l}23.34 \\
(7.46)[38]\end{array}$ & $\begin{array}{l}21.31(8.50)[13] \\
t(70)=-.58, p=.56,95 \% \mathrm{CI}[-6.67,2.60]\end{array}$ & $\begin{array}{l}12.24^{*}(5.86)[21] \\
t(70)=-5.05, p<.001,95 \% \mathrm{CI}[-15.03,-7.18]\end{array}$ \\
\hline Relationship esteem & .91 & $\begin{array}{l}2.05 \\
(3.65)[39]\end{array}$ & $\begin{array}{l}4.62(5.25)[13] \\
t(70)=1.72, p=.09,95 \% \mathrm{CI}[-.40,5.53]\end{array}$ & $\begin{array}{l}6.81^{*}(5.80)[21] \\
t(70)=3.79, p<.001,95 \% \text { CI }[2.25,7.27]\end{array}$ \\
\hline Relationship preoccupation & .85 & $\begin{array}{l}1.72 \\
(2.59)[39]\end{array}$ & $\begin{array}{l}3.15(4.58)[13] \\
t(70)=1.56, p=.13,95 \% \mathrm{CI}[-.41,3.28]\end{array}$ & $\begin{array}{l}1.76(1.95)[21] \\
t(70)=.06, p=.96,95 \% \mathrm{CI}[-1.51,1.60]\end{array}$ \\
\hline Relationship motivation & .96 & $\begin{array}{l}5.87 \\
(7.25)[39]\end{array}$ & $\begin{array}{l}8.92(7.05)[13] \\
t(70)=1.35, p=.18,95 \% \mathrm{CI}[-1.44,7.55]\end{array}$ & $\begin{array}{l}7.90(6.60)[21] \\
t(70)=1.07, p=.29,95 \% \mathrm{CI}[-1.77,5.83]\end{array}$ \\
\hline Relationship anxiety & .95 & $\begin{array}{l}15.36 \\
(6.05)[39]\end{array}$ & $\begin{array}{l}12.62(6.24)[13] \\
t(70)=-1.34, p=.19,95 \% \mathrm{CI}[-6.82,1.33]\end{array}$ & $\begin{array}{l}8.76^{*}(7.03)[21] \\
t(70)=-3.82, p<.001,95 \% \mathrm{CI}[-10.03,-3.16]\end{array}$ \\
\hline Relationship depression & .94 & $\begin{array}{l}13.20 \\
(5.93)[39]\end{array}$ & $\begin{array}{l}12.07(7.55)[13] \\
t(70)=-.57, p=.57,95 \% \mathrm{CI}[-5.08,2.82]\end{array}$ & $\begin{array}{l}7.62 *(5.72)[21] \\
t(70)=-3.34, p=.001,95 \% \mathrm{CI}[-8.92,-2.25]\end{array}$ \\
\hline Fear of Relationships & .92 & $\begin{array}{l}16.28 \\
(5.45)[39]\end{array}$ & $\begin{array}{l}15.08 \text { (5.09) }[13] \\
t(70)=-.66, p=.51,95 \% \mathrm{CI}[-4.83,2.42]\end{array}$ & $\begin{array}{l}11.43^{*}(6.39)[21] \\
t(70)=-3.16, p=.002,95 \% \mathrm{CI}[-7.92,-1.79]\end{array}$ \\
\hline Relationship satisfaction & .85 & $\begin{array}{l}5.13 \\
(5.57)[39]\end{array}$ & $\begin{array}{l}5.46(5.09)[13] \\
t(70)=.20, p=.84,95 \% \mathrm{CI}[-3.27,3.94]\end{array}$ & $\begin{array}{l}6.48(6.06)[21] \\
t(70)=.88, p=.38,95 \% \mathrm{CI}[-1.70,4.39]\end{array}$ \\
\hline Child abuse total & .95 & $\begin{array}{l}88.25 \\
(22.60)[36]\end{array}$ & $\begin{array}{l}75.85 \text { (17.57) }[13] \\
t(68)=-1.51, p=.13,95 \% \mathrm{CI}[-25.95,1.14]\end{array}$ & $\begin{array}{l}54.24^{*}(19.86)[21] \\
t(68)=-5.38, p<.001,95 \% \mathrm{CI}[-45.51,-22.52]\end{array}$ \\
\hline
\end{tabular}

$* p<.05$ in comparison to DD group.

predicting reduced relationship esteem. Complex PTSD symptoms without dissociation were the only predictor of fear of relationships.

The DD sample had more self-reported Schneiderian, borderline and dissociative symptoms than the Chr-PTSD and MP samples. In addition, compared to the MP group, the DD group had more state and trait shame and guilt, were more likely to respond with withdrawal to shame activation, had higher complex PTSD symptoms, with and without dissociation, reported more relationship anxiety, relationship depression and fear of relationships, and had greater child maltreatment severity. They also reported a reduced tendency to attack others in response to shame activation, had less state pride and acknowledged a less positive view of themselves as intimate partners, compared to the MP group. The three groups did not differ on relationship satisfaction, relationship motivation or relationship preoccupations, with all groups showing quite low levels of desire for, and happiness and absorption in, intimate relationships. Moreover, all groups utilized a similar level of avoidance and self-attack in response to shame activation, with self attack in particular registering high scores in all groups.
Studies typically find the greatest difference in symptom profile between severe dissociative disorders and anxiety/depressive disorders, and the least difference between severe dissociative disorders and posttraumatic disorders (Rodewald et al., 2011). In the current study only severe psychiatric symptoms (Schneiderian, borderline, dissociative) differentiated DD from Chr-PTSD, the latter including a potentially large number of participants with dissociative PTSD. It seems the so-called positive symptoms of schizophrenia, borderline symptoms and the pathological manifestations of dissociation may discriminate those with severe dissociative disorders from those with chronic/dissociative PTSD or less severe dissociative disorders. Empirical work has noted the high prevalence of Schneiderian, borderline and pathological dissociative symptoms in severe dissociative disorders (Ellason et al., 1996; Fink and Golinkoff, 1990; Laddis and Dell, 2012; Ross et al., 1990), but few studies have used child abuse-related chronic PTSD comparison groups whose abuse severity overall was similar to those of the DD group. Interestingly, a study of the same data set examining abuse and neglect more closely found that the DD and Chr-PTSD samples were similar on all forms of abuse 
Table 3

Regression model for relationship esteem, relationship anxiety, relationship depression, and fear of relationships.

\begin{tabular}{|c|c|c|c|c|}
\hline & B & SE B & Beta & $\Delta R^{2}$ \\
\hline \multicolumn{5}{|l|}{ Relationship esteem } \\
\hline Step 1 & & & & $.19 * *$ \\
\hline Complex PTSD (without dissociation) & -.29 & .09 & $-.51^{* *}$ & \\
\hline Total CTQ & .02 & .03 & .09 & \\
\hline Trait Guilt & .06 & .17 & .06 & \\
\hline Step 2 & & & & $.07 *$ \\
\hline Complex PTSD (without dissociation) & -.20 & .10 & $-.36^{*}$ & \\
\hline Total CTQ & .03 & .03 & .16 & \\
\hline Trait guilt & .16 & .17 & .14 & \\
\hline Trait shame & -.26 & .11 & $-.37^{*}$ & \\
\hline Step 3 & & & & .02 \\
\hline Complex PTSD (without dissociation) & -.18 & .10 & -.32 & \\
\hline Total CTQ & .05 & .03 & .24 & \\
\hline Trait guilt & .18 & .17 & .16 & \\
\hline Trait shame & -.23 & .11 & $-.34^{*}$ & \\
\hline Path. Dissociation & -.04 & .03 & -.20 & \\
\hline Step 4 & & & & .02 \\
\hline Complex PTSD (without dissociation) & -.19 & .10 & $-.33^{\mathrm{a}}$ & \\
\hline Total CTQ & .04 & .03 & .22 & \\
\hline Trait guilt & .17 & .17 & .15 & \\
\hline Trait shame & -.21 & .11 & $-.30^{\mathrm{a}}$ & \\
\hline Path. Dissociation & -.04 & .03 & -.21 & \\
\hline Shame $\times$ dissociation & .00 & .00 & .13 & \\
\hline \multicolumn{5}{|l|}{ Relationship anxiety } \\
\hline Step 1 & & & & 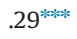 \\
\hline Complex PTSD (without dissociation) & .23 & .12 & $.30^{\mathrm{a}}$ & \\
\hline Total CTQ & .06 & .03 & .23 & \\
\hline Trait guilt & .16 & .22 & .10 & \\
\hline Step 2 & & & & $.05^{*}$ \\
\hline Complex PTSD (without dissociation) & .13 & .13 & .17 & \\
\hline Total CTQ & .05 & .03 & .17 & \\
\hline Trait guilt & .04 & .22 & .03 & \\
\hline Trait shame & .30 & .14 & $.31^{*}$ & \\
\hline Step 3 & & & & .01 \\
\hline Complex PTSD (without dissociation) & .11 & .13 & .14 & \\
\hline Total CTQ & .03 & .04 & .11 & \\
\hline Trait guilt & .03 & .22 & .02 & \\
\hline Trait shame & .27 & .14 & $.29^{\mathrm{a}}$ & \\
\hline Path. Dissociation & .04 & .04 & .15 & \\
\hline Step 4 & & & & .02 \\
\hline Complex PTSD (without dissociation) & .12 & .13 & .15 & \\
\hline Total CTQ & .03 & .04 & .13 & \\
\hline Trait guilt & .04 & .22 & .02 & \\
\hline Trait shame & .24 & .14 & .26 & \\
\hline Path. Dissociation & .04 & .04 & .17 & \\
\hline Shame $\times$ dissociation & -.01 & .01 & -.13 & \\
\hline \multicolumn{5}{|l|}{ Relationship depression } \\
\hline Step 1 & & & & $.14^{*}$ \\
\hline Complex PTSD (without dissociation) & .23 & .12 & .31 & \\
\hline Total CTQ & -.01 & .04 & -.12 & \\
\hline Trait guilt & .15 & .23 & .10 & \\
\hline Step 2 & & & & .02 \\
\hline Complex PTSD (without dissociation) & .16 & .13 & .22 & \\
\hline Total CTQ & -.01 & .04 & -.06 & \\
\hline Trait guilt & .07 & .23 & .05 & \\
\hline Trait shame & .20 & .15 & .22 & \\
\hline Step 3 & & & & $.07 *$ \\
\hline Complex PTSD (without dissociation) & .10 & .13 & .14 & \\
\hline Total CTQ & -.05 & .04 & -.20 & \\
\hline Trait guilt & .03 & .22 & .02 & \\
\hline Trait shame & .14 & .14 & .16 & \\
\hline Path. Dissociation & .09 & .04 & $.38^{*}$ & \\
\hline Step 4 & & & & .00 \\
\hline Complex PTSD (without dissociation) & .20 & .13 & .14 & \\
\hline Total CTQ & -.05 & .04 & -.20 & \\
\hline Trait guilt & .03 & .23 & .02 & \\
\hline Trait shame & .14 & .15 & .16 & \\
\hline Path. Dissociation & .09 & .04 & $.38^{*}$ & \\
\hline Shame $\times$ dissociation & .00 & .00 & .00 & \\
\hline \multicolumn{5}{|l|}{ Fear of relationships } \\
\hline Step 1 & & & & $.30^{* * * * *}$ \\
\hline Complex PTSD (without dissociation) & .40 & .10 & $.59^{* * * * *}$ & \\
\hline Total CTQ & -.01 & .03 & -.05 & \\
\hline
\end{tabular}


Table 3 (continued)

\begin{tabular}{|c|c|c|c|c|}
\hline & B & SE B & Beta & $\Delta R^{2}$ \\
\hline Trait guilt & -.03 & .19 & -.02 & \\
\hline Step 2 & & & & .008 \\
\hline Complex PTSD (without dissociation) & .36 & .11 & $.54^{* * *}$ & \\
\hline Total CTQ & -.02 & .03 & -.08 & \\
\hline Trait guilt & -.07 & .19 & -.05 & \\
\hline Trait shame & .11 & .12 & .13 & \\
\hline Step 3 & & & & .004 \\
\hline Complex PTSD (without dissociation) & .35 & .11 & $.52^{* * *}$ & \\
\hline Total CTQ & -.03 & .03 & -.11 & \\
\hline Trait guilt & -.08 & .19 & -.06 & \\
\hline Trait shame & .09 & .12 & .11 & \\
\hline Path. Dissociation & .02 & .03 & .09 & \\
\hline Step 4 & & & & .000 \\
\hline Complex PTSD (without dissociation) & .35 & .11 & $.52^{* * * *}$ & \\
\hline Total CTQ & -.03 & .03 & -.11 & \\
\hline Trait guilt & -.08 & .20 & -.06 & \\
\hline Trait shame & .09 & .13 & .11 & \\
\hline Path. Dissociation & .02 & .03 & .09 & \\
\hline Shame $\times$ dissociation & -.01 & .00 & -.02 & \\
\hline
\end{tabular}

severity except sexual abuse, where the DD group was higher (Dorahy et al., in preparation). This is consistent with the high levels of sexual abuse reported in severe dissociative disorders (e.g., Boon and Draijer, 1993; Middleton and Butler, 1998; Putnam et al., 1986; Ross and Ness, 2010; Ross et al., 1989b). Several theoretical models suggest dissociation may underpin borderline and Schneiderian symptoms in traumatized samples (Dell, 2009; Van der Hart et al., 2006). As such, higher levels of pathological dissociation, partly associated with child abuse (e.g., sexual abuse), may lead to more severe psychiatric symptoms in DDs compared to Chr-PTSD. Pathological dissociation may reflect a marker of severe psychopathology.

The fact that the predictor variables (childhood abuse/neglect, complex PTSD symptoms without dissociation, trait guilt, trait shame, pathological dissociation) accounted for around a quarter to a third of variance in relationship self-concept markers, underscores the complex nature of the latter variables. Shame and dissociation were not universal predictors of relationship anxiety, depression, fear and esteem, but rather impacted uniquely on specific aspects of relationship self-concept. Shame fell marginally short of significantly predicting lower relationship esteem $(p=.055)$. When activated, shame is a potently disorganizing experience, disrupting cognitive processes (e.g., blank mind), behavioural intentions and affective stability (Hahn, 2009; Herman, 2011, Wilson et al., 2006), as well as eroding interpersonal and intimate relations (Herman, 2011; Kluft, 2007; Mollon, 2006). In this study of abuse and neglect survivors with significant psychiatric illnesses, the relational effect of shame was most associated with reduced esteem. The impact of shame on reducing one's sense of being an adequate intimate partner is likely to be brought about in this study by the "attack self" behavioural script in response to shame (Nathanson, 1992), which was elevated in all participants. Responding to the activation of shame by attacking the self erodes one's general view of the self as acceptable to others, thereby eroding the view of self as a worthy relationship partner.

Pathological dissociation uniquely predicted relationship depression. Relationship depression assessed the experience of being unhappy, discouraged, depressed and disappointed about intimate relationships. Experiencing dissociation as a routine aspect of engaging with intimate partners is likely to produce a felt sense of isolation and disconnection in those relationships, which may promote appraisals of discouragement and disappointment, and feelings of sadness. Future research needs to determine (1) the degree to which dissociation is experienced during (e.g., numbing, depersonalization) and after (e.g., amnesia) intimate engagement, and (2) whether such experiences are related to negative appraisals and feelings about those relationships. It also needs to be determined to what degree chronic dissociative symptoms, and having a sense of self that is organized in a dissociative manner (Van der Hart et al., 2006), contributes to relationship self-concept, beyond acute experiences during intimate engagement.

Dorahy et al. (2013) found that dissociative experiences as measured by total DES scores predicted fear of relationships and relationship preoccupation in a civil conflict-related PTSD sample. That study did not examine the predictive power of pathological dissociation in isolation, nor was the level of child abuse and neglect assessed. Yet overall the mean level of dissociation was comparable in that chronic PTSD sample (30.48) to the combined mean in this study (33.98). Together the two studies suggest that dissociation makes a significant contribution to relationship selfconcept in trauma-related disorders, but subtle differences might be evident in what dissociation predicts depending on the nature of the sample (e.g., more child abuse) and the whether pathological or trait dissociation markers are used. Consistent with Dorahy et al. (2013), this study found that complex PTSD symptoms predicted fear of relationship. In this study the dissociative symptoms were removed, suggesting the conglomeration of other complex PTSD symptoms, which may be underpinned by dissociation at a structural or personality level (Van der Hart et al., 2005), contribute to increasing fear associated with being involved in relationships. Given the interpersonal maltreatment histories of all participants and the connexion between such histories and complex PTSD (Dorahy et al., 2009; McLean and Gallop, 2003; Spitzer et al., 2006), it is perhaps unsurprising that complex PTSD is associated with relationship fear.

The study contained limitations impacting data interpretation and generalizability. The Chr-PTSD was small and seemingly contained a mixture of those with chronic classic PTSD and those with what the current DSM (DSM-5, American Psychiatric Association, 2013) calls dissociative PTSD (Dorahy and Van der Hart, in press; Lanius et al., 2012). Thus, they were not a homogenous sample of PTSD patients. Participants opted into the study following a written invitation from a clinician involved in their 
care. Thus, the degree to which they represent DD, Chr-PTSD and MP samples was not controlled. While only a small number declined to be involved, there was no attempt to quantify this. Finally, some of the relationship subscales required participants to think of a specific intimate relationship. Targeting specific relationships was often difficult for participants in the DD and ChrPTSD groups who not uncommonly reported avoiding truly intimate relationships, or having relationships in which little intimacy existed. More careful assessment of the meaning and nature of intimacy in severely dissociative and chronic trauma disorders is warranted. Therapy for severe and chronically traumatized individuals has increasingly emphasized the importance of addressing shame and dissociation for recovery (e.g., Boon et al., 2011; Chu, 2011; Middleton, 2005). Acknowledging the limitations, this study suggests that such an emphasis may have an impact on how the person perceives one-self and feels in relationships.

\section{Conflicts of interest}

None.

\section{Relationship self-concept in dissociative disorders}

The authors had no conflicts of interest. There was no funding attached to this research. The following contribution were made: MD: Design, data collection, analysis, write-up

WM: Recruitment, data collection

LS: Recruitment, data collection

PM: Recruitment

MW: Recruitment

RC: Recruitment

\section{References}

American Psychiatric Association, 2013. Diagnostic and statistical manual of mental disorders, fifth ed. Author, Washington, DC.

Andrews, B., Brewin, C.R., Rose, S., Kirk, M., 2000. Predicting PTSD symptoms in victims of violent crime: the role of shame, anger and childhood abuse. J. Abnorm. Psychol. 109, 69-73.

Bernstein, D.P. Fink, L., 1998. Childhood trauma questionnaire: a retrospective selfreport. The Psychological Corporation, San Antonio.

Boon, S., Draijer, N., 1993. Multiple personality disorder in the Netherlands: a clinical investigation of 71 patients. Am. J. Psychiatr. 150, 489-494.

Boon, S., Steele, K., Van der Hart, O., 2011. Coping with trauma-related dissociation: skills training for patients and therapists. Norton, New York/London.

Budden, A., 2009. The role of shame in posttraumatic stress disorder: a proposal for a socio-emotional model for DSM-V. Soc. Sci. Med. 69, 1032-1039.

Carlson, E.B., Putnam, F.W., 1993. An update on the dissociative experiences scale. Dissociation 6, 16-27.

Chu, J.A., 2011. Rebuilding shattered lives: treating complex post-traumatic and dissociative disorders, second ed. Wiley, New York.

Dalenberg, C.J., Brand, B.L., Gleaves, D.H., Dorahy, M.J., Loewenstein, R.J., Cardeña, E. Frewen, P.A. Carlson, E.B., Spiegel, D. 2012. Evaluation of the evidence for the trauma and fantasy models of dissociation. Psychol. Bull. 138, 550-588.

Dell, P.F., 2009. Understanding dissociation. In: Dell, P.F., O'Neil, J.A. (Eds.), Dissociation and the Dissociative Disorders: DSM-V and Beyond. Routledge, New York, NY, pp. 709-825.

Dorahy, M.J., 2010. The impact of dissociation, shame, and guilt on interpersonal relationships in chronically traumatized individuals: a pilot study. J. Trauma. Stress 23, 653-656.

Dorahy, M.J., Brand, B.L., Şar, V., Krüger, C., Stavropoulos, P., Martínez-Taboas, A. Lewis-Fernández, R., Middleton, W., 2014. Dissociative identity disorder: an empirical overview. Aust. N. Z. J. Psychiatry 48 (5), 402-417.

Dorahy, M.J., Corry, M., Shannon, M., MacSherry, A., Hamilton, G., McRobert, G., Elder, R., Hanna, D., 2009. Complex PTSD, interpersonal trauma and relational consequences: findings from a treatment-receiving Northern Irish sample. J. Affect. Disord. 112, 71-80.

Dorahy, M.J., Corry, M., Shannon, M., Webb, K., McDermott, B., Ryan, M., Dyer, K.F.W 2013. Complex trauma and intimate relationships: the impact of shame, guilt and dissociation. J. Affect. Disord. 147, 72-79.

Dorahy, M.J., Middleton, W., Seager, L., Williams, M., McGurrin, P., Chambers, R. Child Abuse Neglect Dissociative Identity Disord. (in preparation).
Dorahy, M.J., Schumaker, J.F., 1997. Dissociative functioning and its relationship to state and trait guilt in the non-clinical population. Pers. Individ. Differ. 23, 967-972.

Dorahy, M.J., Van der Hart, O., DSM-5's "PTSD with Dissociative Symptoms": challenges and future directions. J. Trauma Dissoc. http://dx.doi.org/10.1080/ 15299732.2014.908806, in press.

Elison, J., Lennon, R., Pulos, S., 2006. Investigating the compass of shame: the development of the compass of shame scale. Soc. Behav. Pers. 34, 221-238.

Ellason, J.W., Ross, C.A., Fuchs, D.L., 1996. Lifetime Axis I and II comorbidity and childhood trauma history in dissociative identity disorder. Psychiatry 59, 255-266.

Field, A., 2013. Discovering Statistics Using IBM SPSS statistics, fourth ed. Sage, London.

Fink, D., Golinkoff, M., 1990. MPD, borderline personality disorder and schizophrenia: a comparative study of clinical features. Dissociation 3, 127-134.

Ford, J.D., Hawke, J., Alessi, S., Ledgerwood, D., Petry, N., 2007. Psychological trauma and PTSD symptoms as predictors of substance dependence treatment outcome. Behav. Res. Ther. 45, 2417-2431.

Gilbert, P., McGuire, M., 1998. Shame, status and social role. the psychobiological continuum from monkeys to humans. In: Gilbert, P., Andrews, B. (Eds.), Shame, Interpersonal Behaviour, Psychopathology and Culture. Oxford University Press, New York, pp. 99-125.

Gruenewald, T.L., Dickerson, S.S., Kemeny, M.E., 2007. A social function for self-conscious emotions: the social self preservation theory. In: Tracy, J.L., Robins, R.W., Tangney, J.P. (Eds.), The Self-Conscious Emotions: Theory and Research. Guilford Press, New York, pp. 68-87.

Hahn, W.K., 2009. Shame. In: O'Donohue, W., Graybar, S.R. (Eds.), Handbook of Contemporary Psychotherapy: Towards an Improved Understanding of Effective Psychotherapy. Sage, Los Angeles, pp. 303-320.

Harder, D.W., 1995. Shame and guilt assessment, and relationships of shame- and guilt-proneness to psychopathology. In: Tangney, J.P., Fischer, K.W. (Eds.), SelfConscious Emotions: The Psychology of Shame, Guilt, Embarrassment, and Pride. Guilford, New York, pp. 368-392.

Harder, D.W., Lewis, S.J., 1987. The assessment of shame and guilt. In: Spielberger C., Butcher, J.N. (Eds.), Advances in Personality Assessment, vol. 6. Lawrence Erlbaum, Hillsdale, NJ, pp. 89-114.

Herman, J.L., 2011. PTSD as a shame disorder. In: Dearing, R.L., Tangney, J.P. (Eds.), Shame in the Therapy Hour. American Psychological Association, Washington, DC.

Hinde, R., Finkenauer, C., Auhagen, A.E., 2001. Relationships and the self concept. Pers. Relat. 8, 187-204.

Howell, E.F., 2011. Understanding and Treating Dissociative Identity Disorder. Routledge, New York.

Irwin, H.J., 1998. Affective predictors of dissociation-II: shame and guilt. J. Clin. Psychol. 54, 237-245.

Kluft, R.P., 2007. Applications of innate affect theory to the understanding and treatment of dissociative identity disorder. In: Vermetten, E., Dorahy, M.J., Spiegel, D. (Eds.), Traumatic Dissociation: Neurobiology and Treatment. American Psychiatric Press, Inc., Arlington, VA, pp. 301-316.

Laddis, A., Dell, P.F., 2012. Dissociation and psychosis in dissociative identity disorder and schizophrenia. J. Trauma Dissoc. 13, 397-413.

Lanius, R.A., Brand, B., Vermetten, E., Frewen, P.A., Spiegel, D., 2012. The dissociative subtype of posttraumatic stress disorder: rationale, clinical and neurobiological evidence, and implications. Depress. Anxiety 29, 701-708.

Lee, D.A., Scragg, P., Turner, S., 2001. The role of shame and guilt in traumatic events: a clinical model of shame-based and guilt-based PTSD. Brit. J. Med. Psychol. 74, 451-466.

Lyons-Ruth, K., 2003. Dissociation and the parent-infant dialogue: a longitudinal perspective from attachment research. J. Am. Psychoanal. Assoc. 51, 883-911.

Lyons-Ruth, K., 2008. From infant attachment disorganisation to adult dissociation. Plenary Paper Presented at the First Biannual Conference of the European Society for Trauma and Dissociation. Amsterdam.

Marschall, D.E., Sanftner, J.L., Tangney, J.P., 1994. The State Shame and Guilt Scale. George Mason University, Fairfax, VA.

McLean, L.M., Gallop, R., 2003. Implications of childhood sexual abuse for adult borderline personality and complex posttraumatic stress disorder. Am. J. Psychiatry 160, 369-371.

Middleton, W., 2005. Owning the past, claiming the present: perspectives on the treatment of dissociative patients. Aust. Psychiatry 13, 40-49.

Middleton, W., 2012. Trauma and selfhood. In: Figley, C.R. (Ed.), Encyclopedia of Trauma: An Interdisciplinary Approach. Sage, London, pp. 693-696.

Middleton, W., Butler, J., 1998. Dissociative identity disorder: an Australian series. Aust. N. Z. J. Psychiatry 32, 794-804.

Mollon, P., 2006. Shame and Jealousy: The Hidden Turmoils. Karnac, London.

Nathanson, D.L., 1992. Shame and Pride: Affect, Sex, and the Birth of the Self. Norton, New York.

Nijenhuis, E.R.S., Van Dyck, R., Spinhoven, P., Van der Hart, O., Chatrou, M, Vanderlinden, J., Moene, F., 1999. Somatoform dissociation discriminates between diagnostic categories over and above general psychopathology. Aust. N. Z. J. Psychiatry 33, 512-520.

Pelcovitz, D., Van der Kolk, B.A., Roth, S., Mandel, F., Kaplan, S., Resick, P., 1997. Development of a criteria set and a structured interview for disorders of extreme stress (SIDES). J. Trauma. Stress 10, 3-16.

Putnam, F.W., Guroff, J.J., Silberman, E.K., Barban, L., Post, R.M., 1986. The clinical phenomenology of multiple personality disorder: review of 100 recent cases. J. Clin. Psychiatry 47, 285-293. 
Rodewald, F., Wilhelm-Gößling, C., Emrich, H.M., Reddemann, L., Gast, U., 2011. Axis-I comorbidity in female patients with dissociative identity disorder and dissociative identity disorder not otherwise specified. J. Nerv. Ment. Dis. 199, $122-131$.

Ross, C.A., 1995. The validity and reliability of dissociative identity disorder. In: Cohen, L.M., Berzoff, J.N., Elin, M.R. (Eds.), Dissociative identity disorder: Theoretical and Treatment Controversies. Aronson, Northvale, NJ, pp. 65-84.

Ross, C.A., Heber, S., Norton, G.R., Anderson, D., Anderson, G., Barchet, P., 1989a. The dissociative disorders interview schedule: a structured interview. Dissociation 2, 169-189.

Ross, C.A., Miller, S.D., Reagor, P., Bjornson, L., Fraser, G.A., Anderson, G., 1990. Schneiderian symptoms in multiple personality disorder and schizophrenia. Compr. Psychiatry 31, 111-118.

Ross, C.A., Ness, L., 2010. Symptom patterns in dissociative identity disorder patients and the general population. J. Trauma Dissoc. 11, 458-468.

Ross, C.A., Norton, G.R., Wozney, K., 1989b. Multiple personality disorder: an analsyis of 236 cases. Can. J. Psychiatry 34, 413-418.

Şar, V., Yargic, L.I., Tutkun, H., 1996. Structured interview data on 35 cases of dissociative identity disorder in Turkey. Am. J. Psychiatry 153, 1329-1333.

Snell, W.E., Schicke, M., Arbeiter, T., 1996. The Multidimensional Relationship Questionnaire: psychological dispositions associated with intimate relations. Unpublished manuscript.

Spitzer, C., Chevalier, C., Gillner, M., Freyberger, H.J., Barnow, S., 2006. Complex posttraumatic stress disorder and child maltreatment in forensic inpatients. J. Forensic Psychiatry Psychol. 17, 204-216.
Talbot, J.A., Talbot, N.L., Tu, X., 2004. Shame-proneness as a diathesis for dissociation in women with histories of childhood sexual abuse. J Trauma. Stress 17, $445-448$.

Tangney, J.P., 1996. Conceptual and methodological issues in the assessment of shame and guilt. Behav. Res. Ther. 34, 741-754.

Tangney, J.P., Dearing, R.L., 2002. Shame and Guilt. Guilford Press, New York.

Thomson, P., Jaque, S.V., 2013. Exposing shame in dancers and athletes: shame, trauma, and dissociation in a nonclinical population. J. Trauma Dissoc. 14, 439-454.

Tracy, J.L., Robins, R.W., 2007. The self in self-conscious emotions: a cognitive appraisal approach. In: Tracy, J.L., Robins, R.W., Tangney, J.P. (Eds.), The SelfConscious Emotions: Theory and Research. Guilford Press, New York, pp. 3-20.

Van der Hart, O., Nijenhuis, E., Steele, K., 2005. Dissociation: an insufficiently recognized major feature of complex PTSD. J. Trauma. Stress 18, 413-423.

Van der Hart, O., Nijenhuis, E.R.S., Steele, K., 2006. The Haunted Self: Structural Dissociation and the Treatment of Chronic Traumatization. Norton, New York.

Van IJzendoorn, M.H., Schuengel, C., 1996. The measurement of dissociation in normal and clinical populations: meta-analytic validation of the Dissociative Experiences Scale (DES). Clin. Psychol. Rev. 16, 365-382.

Waller, N.G., Putnam, F.W., Carlson, E.B., 1996. Types of dissociation and dissociative types. Psychol. Methods 1, 300-321.

Wilson, J.P., Drozdek, B., Turkovic, S., 2006. Posttraumatic shame and guilt. Trauma Viol. Ab 7, 122-141. 